$\mathbf{R}_{\text {ESEARCH }} \mathbf{P}_{\text {APER }}$

\title{
Nutritional evaluation and product development by using green papaya, flaxseed and maize flour to promote the traditional food
}

\author{
Vinita Singh, Reema Verma and Kaushal Kumar
}

\begin{abstract}
Papaya (Carica papaya) is an excellent source of vitamin A and vitamin C. Papaya and maize flour contain lutein and zeaxanthin, known as xanthophylls. A good intake of both lutein and zeaxanthin is believed to significantly reduce our risk of developing age-related macular degeneration (ARMD), the most common cause of blindness in America. Flaxseed contain omega 3- fatty acid which is important for life. Biochemical analysis of prepared products revealed that III (50:35:15) incorporated Laddoos, I (50:45:5) incorporated cutlet contain high amount of protein carbohydrate and fat, moderate amount of calcium and good amount of vitamin A. Incorporated products (Laddoos and cutlet) had better quality with respect to nutrition.
\end{abstract}

Key Words : Green papaya, Flaxseed, Maize, Papain, Lutein, Zeaxanthin, Xanthophylls, Nutritive value

How to cite this article : Singh, Vinita, Verma, Reema and Kumar, Kaushal (2015). Nutritional evaluation and product development by using green papaya, flaxseed and maize flour to promote the traditional food. Food Sci. Res. J., 6(1): 8-13. 